\title{
SUCO DE CAJU COMO FONTE DE CARBONO PARA A PRODUÇÃO DE CELULOSE BACTERIANA: UMA INVESTIGAÇÃO PRELIMINAR SOBRE O TEMA
}

\author{
Helder L. S. Lima ${ }^{1}$, Eligenes S. Nascimento ${ }^{1}$, Matheus de O. Barros ${ }^{2}$, Maria K. de A. \\ Barroso $^{1}$, Ana I. S. Brígida ${ }^{3}$, Maria de F. Borges ${ }^{4}$, Morsyleide de F. Rosa ${ }^{4}$ \\ ${ }^{1}$ Universidade Federal do Ceará - UFC. Departamento de Engenharia Química. Departamento de Tecnologia \\ de Alimentos \\ ${ }^{2}$ Instituto Federal do Ceará - IFCE. Departamento de Processos Químicos \\ ${ }^{3}$ Embrapa Agroindustria de Alimentos \\ ${ }^{4}$ Embrapa Agroindustria Tropical
}

E-mail para contato: morsyleide.rosa@embrapa.br

\section{RESUMO}

A celulose bacteriana é um material polimérico natural de aplicação ampla em várias áreas tecnológicas. No presente trabalho avaliou-se a produção de celulose bacteriana $(C B)$ pela bactéria Gluconacetobacter hansenii CCT 1431 por meio de fermentação submersa estática, utilizando suco de caju como fonte de carbono alternativa. O efeito da diluição do suco na produção foi investigado. A produção da película de CB foi observada na faixa de diluição entre 20 a $100 \mathrm{~g} / \mathrm{L}$ de açúcares totais, com maiores produções a partir de $50 \mathrm{~g} / \mathrm{L}$.

\section{INTRODUÇÃO}

Desde sua descoberta, a celulose bacteriana (CB) tem despertado grande interesse por parte dos pesquisadores pois trata-se de um material polimérico que apresenta propriedades e características especiais, possibilitando uma ampla aplicação que inclui o desenvolvimento de dispositivos médicos, compósitos resistentes, materiais biodegradáveis além de aplicações nas áreas farmacêutica e alimentar. A CB apresenta alta resistência mecânica, alto índice de 


\section{SIMPÓSIO NACIONAL DE BIOPROCESSOS \\ XI SIMPÓSIO DE HIDRÓLISE ENZIMÁTICA DE BIOMASSA}

01 a 04 de setembro de 2015

Fortaleza, Ceará, Brasil

cristalinidade, alta absorção de água e biocompatibilidade. Quando obtida por processo fermentativo em cultivo estático, apresenta-se sob a forma de uma película. A CB é obtida principalmente pelo cultivo de bactérias do gênero Gluconacetobacter em meio contendo açúcares e nitrogênio orgânico (Chawla et al., 2009; Donini et al., 2010; Shi et al., 2013).

Diversos substratos alternativos têm sido estudados para a produção de $C B$ e, em muitos casos, é possível alcançar uma produção semelhante ou superior quando se compara com processos que utilizam meios sintéticos (Kurosumi et al., 2009).

No Nordeste a cultura do caju se destaca pela sua importância econômica e quantidade de resíduos gerados em seu beneficiamento. Na produção do caju, cujo principal produto de interesse é a castanha, há um desperdício de $90 \%$ de todo o pedúnculo gerado, que por sua vez representa $90 \%$ do peso total do caju (Fontes et al., 2013). Atualmente, o suco de caju tem sido estudado em processos fermentativos por ser rico em nutrientes e apresentar uma alternativa viável para a produção de biossurfactantes, proteínas unicelulares, oligossacarídeos e outras substâncias (Oliveira et al., 2013). A agregação de valor ao suco de caju pode ser feita por meio da obtenção de produtos biotecnológicos por via fermentativa reduzindo assim o impacto ambiental proveniente da disposição final dessa fonte e reduzindo custos do produto ou processo desenvolvido. $O$ objetivo do presente trabalho consiste em avaliar de forma preliminar a produção de CB por Gluconacetobacter hansenii CCT 1431, através de fermentação submersa estática, utilizando suco de caju como fonte de carbono alternativa.

\section{METODOLOGIA}

\subsection{Caracterização Físico-Química do Suco de Caju}

O pedúnculo do caju foi coletado no Campo Experimental de Pacajus da Embrapa Agroindústria Tropical, lavado e prensado para obtenção do suco. As amostras foram armazenadas a $-18^{\circ} \mathrm{C}$ em frascos e descongeladas no momento da realização dos ensaios. $O$ suco foi caracterizado quanto sua composição de açúcares por HPLC, utilizando coluna Varian PL Hi-Plex Ca 8um (300 x 7.7mm) mantida a 60 드, detector de índice de refração Varian 355 RI Pro Star. Em paralelo, açúcares redutores e totais foram determinados pelo método de DNS descrito por Miller (1959) utilizando glicose como padrão. Para açúcares totais, as amostras foram submetidas à hidrólise ácida previamente. Teor de nitrogênio total pelo método de Kjeldahl (Yasuhara e Nokihara, 2001) e pH por leitura direta em pHmetro.

\subsection{Inoculação, Produção e Purificação de CB}

Após a ativação da linhagem G. hansenii CCT 1431 em caldo HS (Hestrin e Schramm, 1954), os meios estéreis foram adicionados de $3 \%(\mathrm{v} / \mathrm{v})$ de inóculo. Após a inoculação procedeu-se a distribuição de $100 \mathrm{~mL}$ de meio em placa de Petri de $14,5 \mathrm{~cm}$ de diâmetro. A fermentação submersa ocorreu sob condições estáticas a $30^{\circ} \mathrm{C}$ por cinco dias. Durante o processo de 


\section{SIMPÓSIO NACIONAL DE BIOPROCESSOS \\ XI SIMPÓSIO DE HIDRÓLISE ENZIMÁTICA DE BIOMASSA}

01 a 04 de setembro de 2015

Fortaleza, Ceará, Brasil

fermentação, avaliou-se o efeito da diluição do suco de caju na produção e rendimento de $C B$, tomando-se como referência a concentração inicial de açúcares (2,5 a $100 \mathrm{~g} / \mathrm{L})$. A produção de CB em suco de caju foi comparada com a obtida em meio padrão HS. Todos os meios foram ajustados para $\mathrm{pH} 5$.

Após a fermentação, as películas de celulose formadas foram recolhidas e os meios fermentados filtrados e separados para análise de açúcares e pH. O teor de açúcares do meio fermentado foi determinado pelo método de DNS (Miller, 1959). As películas de CB foram purificadas através de tratamento alcalino $\left(100^{\circ} \mathrm{C}, \mathrm{NaOH} 4 \%(\mathrm{~m} / \mathrm{v})\right.$, por 1 hora). Em seguida, as películas foram lavadas em água destilada até a neutralização. A massa de celulose foi determinada por secagem e pesagem da película a 170 ㄷ em balança de infra-vermelho. O rendimento $Y_{P / S}(\%)$ foi calculado de acordo com a equação 1 , onde $\mathrm{mCB}$ é a massa seca de celulose produzida, Si a quantidade de açúcar inicial e Sf a quantidade de açúcar final no meio fermentado.

$Y_{P / S}(\%)=(m C B /(S i-S f)) 100$

\section{RESULTADOS E DISCUSSÃO}

O teor de açúcares totais no suco de caju foi de 107,40 g/L, sendo $70 \%$ deles constituídos por glicose e $30 \%$ de frutose. O teor de nitrogênio foi de $0,32 \mathrm{~g} / \mathrm{L}$ e o $\mathrm{pH}$ natural do suco 4,33 . Uma vez que o suco utilizado no presente estudo possui nitrogênio e grandes quantidades de açúcares, é razoável supor que o mesmo pode desempenhar a função de meio alternativo para processos fermentativos, em especial, para produção de CB que requer esses dois tipos de nutrientes.

A Tabela 1 apresenta a produção e rendimento de CB nas diferentes diluições estudadas. Observase que, para o suco de caju, a linhagem G. hansenii ATCC 23769 apresentou capacidade de sintetizar CB apenas no intervalo de 20 a $100 \mathrm{~g} / \mathrm{L}$ de açúcares com destaque para a concentração de $50 \mathrm{~g} / \mathrm{L}$ onde a produção estabilizou-se $(0,34 \mathrm{~g} / \mathrm{L}$ ) (Tabela 1$)$. O rendimento foi reduzido de $2,95 \%$ a $1,19 \%$ nesse intervalo com consumo de açúcares em torno de $37 \%$. No intervalo de concentração de 2,5 a $15 \mathrm{~g} / \mathrm{L}$ houve consumo crescente de açúcares, os quais foram direcionados para vias metabólicas não referentes a produção de $C B$. Não houve consumo de açúcares ou produção de $C B$ na concentração de $2,5 \mathrm{~g} / \mathrm{L}$, sendo esta uma condição adversa ao desenvolvimento microbiano devido a limitação de nutrientes. $\mathrm{O}$ pH final permaneceu próximo ao inicial $(5,00)$ em todas as concentrações, o que é um indicativo de baixa produção de ácidos orgânicos. A produção de ácidos orgânicos, principalmente o ácido glucônico, é comum no processo produtivo de CB. 


\section{SIMPÓSIO NACIONAL DE BIOPROCESSOS XI SIMPÓSIO DE HIDRÓLISE ENZIMÁTICA DE BIOMASSA}

01 a 04 de setembro de 2015

Fortaleza, Ceará, Brasil

Tabela 1. Efeito da diluição na produção de CB por G. hansenii ATCC 23769, utilizando suco de caju como fonte alternativa de carbono. Letras iguais na coluna não apresentam diferença significativa $(\alpha=0,05)$.

\begin{tabular}{|c|c|c|c|c|c|}
\hline Açúcares (g/L) & $\begin{array}{l}\text { Nitrogênio } \\
\text { (g/L) }\end{array}$ & Celulose (g/L) & $Y_{p / s}(\%)$ & $\begin{array}{c}\text { Açúcar } \\
\text { consumido } \\
\text { (g/L) }\end{array}$ & pH final \\
\hline 2,5 & 0,01 & $0,00 \pm 0,00^{\mathrm{a}}$ & $0,00 \pm 0,00^{\mathrm{a}}$ & $0,00 \pm 0,00^{\mathrm{a}}$ & $5,15 \pm 0,01^{b}$ \\
\hline 5 & 0,01 & $0,00 \pm 0,00^{a}$ & $0,00 \pm 0,00^{a}$ & $0,43 \pm 0,22^{a}$ & $5,11 \pm 0,03^{b}$ \\
\hline 7,5 & 0,02 & $0,00 \pm 0,00^{a}$ & $0,00 \pm 0,00^{a}$ & $1,00 \pm 0,38^{a}$ & $4,94 \pm 0,01^{b}$ \\
\hline 10 & 0,03 & $0,00 \pm 0,00^{\mathrm{a}}$ & $0,00 \pm 0,00^{a}$ & $4,76 \pm 0,47^{b}$ & $5,01 \pm 0,02^{a b}$ \\
\hline 15 & 0,04 & $0,00 \pm 0,00^{a}$ & $0,00 \pm 0,00^{a}$ & $5,92 \pm 0,85^{b}$ & $4,92 \pm 0,01^{a b}$ \\
\hline 20 & 0,06 & $0,21 \pm 0,00^{b}$ & $2,95 \pm 0,00^{b}$ & $6,98 \pm 0,58^{b}$ & $5,02 \pm 0,01^{a b}$ \\
\hline 30 & 0,09 & $0,25 \pm 0,01^{b}$ & $2,80 \pm 0,09^{b}$ & $9,08 \pm 1,08^{b}$ & $5,06 \pm 0,02^{a b}$ \\
\hline 50 & 0,15 & $0,34 \pm 0,04^{c}$ & $1,61 \pm 0,20^{c}$ & $21,16 \pm 1,27^{b}$ & $4,93 \pm 0,00^{\mathrm{ab}}$ \\
\hline 75 & 0,22 & $0,32 \pm 0,02^{c}$ & $0,87 \pm 0,04^{d}$ & $37,22 \pm 1,25^{b}$ & $4,86 \pm 0,01^{a}$ \\
\hline 100 & 0,30 & $0,37 \pm 0,00^{c}$ & $1,19 \pm 0,01^{d}$ & $31,37 \pm 1,06^{b}$ & $4,89 \pm 0,01^{a}$ \\
\hline HS (20 g/L) & 1,25 & $0,54 \pm 0,13^{c}$ & $4,38 \pm 1,04^{c}$ & $12,39 \pm 0,30^{b}$ & $3,48 \pm 0,11^{c}$ \\
\hline
\end{tabular}

A produção nula de CB na faixa de concentração de 2,5 a $15 \mathrm{~g} / \mathrm{L}$ pode ser explicada pela baixa concentração de nitrogênio nos meios que variou de 0,007 a 0,04 g/L. Em comparação com o meio HS que apresenta $1,25 \mathrm{~g} / \mathrm{L}$ de nitrogênio, observa-se que a quantidade de nitrogênio encontra-se bastante limitada. Por outro lado, houve uma boa produção de CB a partir de $50 \mathrm{~g} / \mathrm{L}$ de CB correspondendo a $62 \%$ da produção em meio HS sintético (Figura 1).

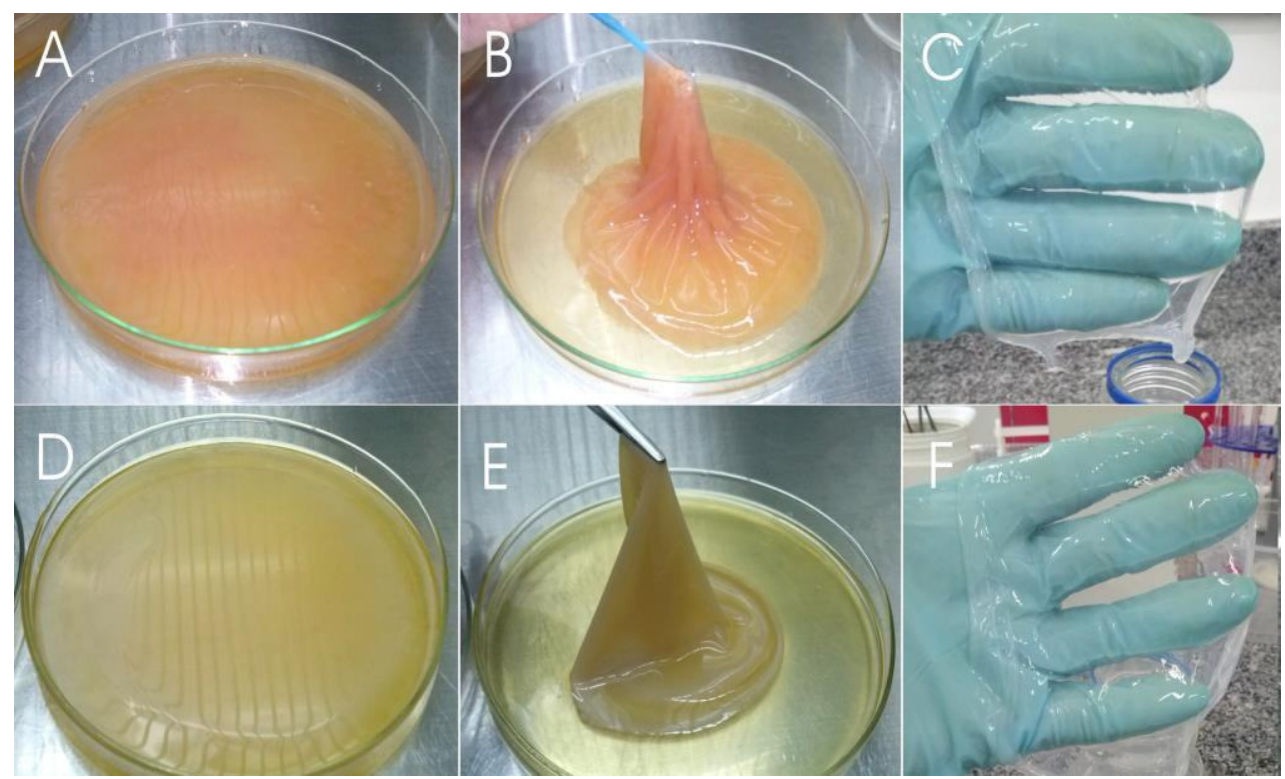

Figura 1. Películas de $C B$ obtidas no presente trabalho: $(A)(B)(C)$ suco de caju, $(D)(E)(F)$ meio $H S,(A)(D)$ película na superfície do meio após 5 dias de cultivo, $(B)(E)$ película sendo removida, (C)(F) película purificada em estado úmido. 


\section{SIMPÓSIO NACIONAL DE BIOPROCESSOS \\ XI SIMPÓSIO DE HIDRÓLISE ENZIMÁTICA DE BIOMASSA}

01 a 04 de setembro de 2015

Fortaleza, Ceará, Brasil

Alguns autores sugerem que a produção de CB pode ser eficiente na faixa de 10 a $20 \mathrm{~g} / \mathrm{L}$ de açúcares, porém, é necessário que o meio contenha quantidade suficiente de nitrogênio orgânico (Keshk et al., 2006; Son et al., 2003).

\section{CONCLUSÃO}

De acordo com os resultados, foi possível obter películas de CB utilizando suco de caju como meio alternativo. As maiores produções foram obtidas com concentração de açúcar superior a $50 \mathrm{~g} / \mathrm{L}$ Convém ressaltar que não houve suplementação do suco e, portanto, melhores resultados podem ser obtidos em estudos futuros considerando essa abordagem.

\section{AGRADECIMENTOS}

Os autores agradecem ao CNPq, FUNCAP e CAPES pelo apoio financeiro e bolsas.

\section{REFERÊNCIAS}

Chawla, P.R., Bajaj, I.B., Survase, S.A., Singhal, R.S., 2009. Microbial cellulose: Fermentative production and applications - Fermentative production of microbial cellulose. Food Technol. Biotechnol. 47, 107-124.

Donini, Í. A.N., Salvi, D.T.B., Fukumoto, F.K., Lustri, W.R., Barud, H.S., Marchetto, R., Messaddeq, Y., Ribeiro, S.J.L., 2010. Biossíntese e recentes avanços na produção de celulose bacteriana. Eclet. Quím. 35, 165-178.

Fontes, C.P.M.L., Silveira, M.A., Guilherme, A.A., Fernandes, F.A.N., Rodrigues, S., 2013. Substitution of yeast extract by ammonium sulfate for mannitol production in cashew apple juice. Biocatal. Agric. Biotechnol. 2, 69-75.

Hestrin, S., Schramm, M., 1954. Synthesis of cellulose by Acetobacter xylinum. Preparation of freeze-dried cells capable of polymerizing glucose to cellulose. Biochem. Journal. 58, 345-352.

Keshk, S., Sameshima, K., 2006. Influence of lignosulfonate on crystal structure and productivity of bacterial cellulose in a static culture. Enzyme Microb. Tech. 40, 4-8.

Kurosuml, A., Sasaki, C., Yamashita, Y., Nakamura, Y., 2009. Utilization of various fruit juices as carbon source for production of bacterial cellulose by Acetobacter xylinum NBRC 13693. Carbohydr. Polym. 76, 333-335. 
Miller, G. L., 1959. Use of dinitrosalicylic acid reagent for determination of reducing sugar. Analyt. Chem., 31, 426-428.

Oliveira, D.W.F., França, Í.W.L., Félix, A.K.N., Martins, J.L., Giro, M.E.A., Melo, V.M.M., Gonçalves, L.R.B., 2013. Kinetic study of biosurfactant production by Bacillus subtilis LAMI005 grown in clarified cashew apple juice. Colloids Surf. B: Biointerfaces. 101, 34-43.

Shi, Z., Zhang, Y., Phillips, G.O., Yang, G., 2013. Utilization of bacterial cellulose in food. Food Hydrocolloids. 35, 539-545.

Son, H., Kim, H., Kim, K., Kim, H. So., Kim, Y., LEE, S., 2003. Increased production of bacterial cellulose by Acetobacter sp. V6 in synthetic media under shaking culture conditions. Bioresour. Technology. 3, 215-219.

Yasuhara, T., Nokihara, K., 2001. High-throughput analysis of total nitrogen content that replaces the classic Kjeldahl method. J. Agric. Food Chem. 49, 4581-4583. 